\title{
MODEL NEURAL NETWORK BERBASIS FORWARD SELECTION UNTUK PREDIKSI JUMLAH PRODUKSI MINYAK KELAPA
}

\author{
Marniyati H. Botutihe \\ Marniyati.h.botutihe@gmail.com \\ Universitas Ichsan Gorontalo
}

\begin{abstract}
Abstrak
Sulitnya memprediksi jumlah produksi dimasa datang sehingga permintaan komsumen seringkali tidak terpenuhi dengan baik. Tujuan penelitian ini adalah untuk membuat model prediksi jumlah produksi minyak kelapa menggunakan metode neural network berbasis forward selection, untuk mengetahui jumlah produksi di masa yang akan datang dengan tingkat error yang lebih rendah. Model yang dipilih berdasarkan nilai Root Mean Square Error (RMSE) terkecil yang diperoleh dari hasil pengujian. Hasil prediksi jumlah produksi minyak kelapa berdasarkan penelitian yang telah dilakukan sebelumnya dengan hasil nilai aktual jumlah produksi minyak kelapa januari 2015, nilai tersebut berdasarkan hasil produksi yang telah terjadi. Dengan rata - rata persentase yang diperoleh yaitu $91,01 \%$.
\end{abstract}

Kata kunci: Produksi Minyak Kelapa, Time Series

\section{Pendahuluan}

Minyak kelapa adalah minyak yang dihasilkan dari kopra (daging buah kelapa yang telah dikeringkan) atau dari perasan santannya. Minyak kelapa penting bagi metabolisme tubuh karena mengandung vitamin - vitamin yang larut dalam lemak, yaitu vitamin $A, D, E$, dan $K$ serta provitamin $A$ (karoten)[1].Sulitnya memprediksi jumlah produksi dimasa datang sehingga permintaan komsumen seringkali tidak terpenuhi dengan baik.Untuk memenuhi tingkat produksi dalam menyeimbangi permintaan komsumen penentuan jumlah produksi harus direncanakan sebagai dasar pengambilan keputusan.Perusahaan diwajibkan menyusun rencana dan menentukan jumlah produksi sehingga permintaan pasar dan konsumen dapat dipenuhi berdasarkan jumlah yang sesuai serta tepat waktu. Penjualan adalah salah satu informasi yang terutama dalam menyusun rencana produksi, karena merupakan suatu titik awal dalam perencanaan produksi. Produksi yang berlebihan merupakan suatu pemborosan atau kerugian terhadap perusahaan sedangkan produksi yang dibawah permintaan pasar memberi kesempatan kepada pesaing untuk memasuki daerah penjualan perusahaan. Sebelum melakukan produksi kita harus mengetahui berapa jumlah produk yang tepat agar perusahaan dapat berjalan secara optimal. Serta menghitung berapa jumlah bahan baku yang harus dipersiapkan oleh perusahaan untuk kelancaran produksinya [2].

Dalam penelitian ini menerapkan model neural network untuk memprediksi jumlah produksi minyak kelapa.Tujuan penelitian ini adalah untuk membuat model prediksi jumlah produksi minyak kelapa menggunakan metode neural network berbasis forward selection, untuk mengetahui jumlah produksi di masa yang akan datang dengan tingkat error yang lebih rendah.

\section{Metode}

Langkah awal pada suatu penelitian adalah pengumpulan data. Data yang digunakan pada penelitian ini adalah data set Sales Order Minyak Kelapa PT. Multi Nabati Sulawesi Unit Maleo. Data yang diperoleh berupa data jam time seriesunivariat. Data tersebut berupa data jumlah penjualan minyak kelapa yaitu data set dari tahun 2012-2014. Data set tersebut untuk hari minggu tidak terjadi transaksi penjualan serta tanggal merah setiap tahunnya kosong dan terdiri dari variable Quantity dengan 635 record yang berasal dari PT. Multi Nabati Unit Maleo Gorontalo.

Data yang diperoleh berupa data univariat times series yang berupa numerik yaitu data jam, kemudian susunan data tersebut dirubah kedalam bentuk data harian sehingga diperoleh dataset sebanyak 635 record. Setelah mengubah data univariat time series yang berupa data jam ke data harian kemudian data diurutkan dari ascending menjadi descending. Selanjutnya data descending diolah dengan metode normalisasi.

Dataset yang telah dinormalisasi masih bersifat univariat diubah lagi menjadi data time series multivariat kemudian dijadikan dalam beberapa variabel independent, misalnya 1 periode sampai 10 periode dengan masing-masing 1 variabel dependent. Tahap selanjutnya menentukan parameter neural network dengan memasukkan nilai training cycle dengan range 100 sampai 1000. Nilai learning 
rate dengan range 0,1 sampai 0,9 . Nilai momentum dengan range 0,1 sampai 0,9 . Menentukan jumlah input layeruntuk melakukan pengujian dengan memasukkan 1 sampai dengan 10 jumlah inputan. Penentuan jumlah hidden layer adalah 1 dan menentukan neuron sizedengan melakukan pengujian dengan memasukkan nilai dengan range 1 sampai 10 serta nilai training cycle, learning rate dan momentumpada pengujian sebelumnya. Selanjutnya melakukan pengujian neural network dengan menentukan parameter terbaik yaitu dengan menggunakan tools rapidminer. Hasil terbaik dari parameter neural networkyaitu nilai training cycle500, nilai learning rate0,3, nilai momentum0,2, nilai neuron size 6. Berikutnya tahap seleksi dengan menggunakan Forward Selectionfungsinya untuk memilih variabel-variabel yang benar-benar terbaik atau variabel yang signifikan agar memberikan hasil yang terbaik. Kemudian melakukan pengujian dengan neural network dan forward selection, neural network dan backward elimination, neural network dan particle swarm optomozation kemudian membandingkan model tersebut hasil terbaik berdasarkan RMSE terkecil yang akan dipilih.

\subsection{Neural Network}

Neural Network merupakan sebuah metode yang bekerja berdasarkan cara kerja otak pada manusia. Informasi dikirim ke neuron melalui suatu pembobotan input. Kemudian input ini diproses oleh fungsi propagation yang akan menaikan nilai bobot input. Hasilnya kemudian dibandingkan dengan threshold oleh fungsi aktifasi, jika input melampaui batas threshold, maka neuron diaktifkan, jika tidak maka neuron akan di inhibit. Jika diaktifkan, neuron akan mengirim output melalui pembobotan output ke neuron lainnya, dan begitu seterusnya. Neural Network dalam data mining digunakan untuk memproses prediksi kelas suatu data uji baru yang ditemukan. Ada banyak proses pelatihan pada neural network, antara lain Perceptron, Backpropagation, Self-Organizing Map (SOM), Deelta, Associative Memory, Learning Quantization, dan sabagainya [3].

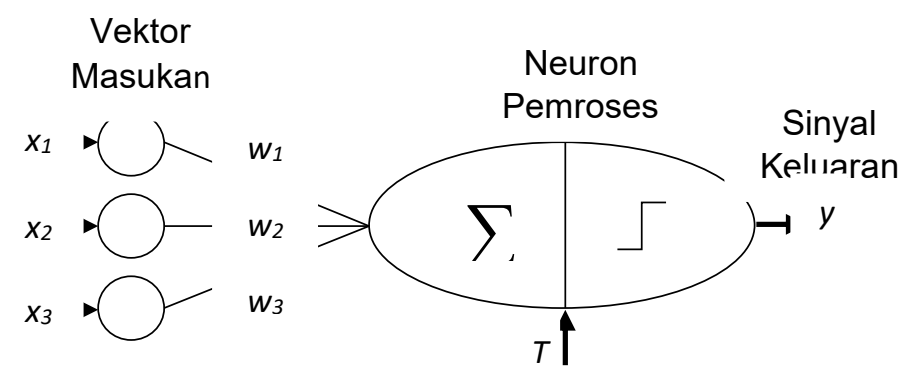

Gambar 1. Desain Umum ANN

\subsection{Seleksi Fitur}

Forward selection yaitu suatu metode yang berfungsi untuk mengoptimalkan kinerja suatu model dengan memilih variabel - variabel yang signifikan. Prosedur bertahap merupakan system kerja dari motode ini adalah menambah variabel yang diujikan satu persatu ke dalam persamaan yang didasarkan pada nilai tertentu atau Alpha untuk masukkan. Apha tersebut menentukan apakah salah satu prediktor yang saat ini tidak dalam model, harus ditambah ke model. Jika nilai dari predictor kurang dari tingkat, sehingga prediktor merupakan kandindat untuk dimasukkan kedalam model.Backward Eleminationmerupakan metode yang berfungsi untuk mengoptimalkan kinerja dari suatu model pemilihan mundur adalah cara kerja dari metode ini. Pemilihan mundur merupakan cara yang dilakukan dalam melakukan pemilihan variabel dengan menguji variabel selanjutnya membuang variabel - variabel yang tidak signifikan. Hanya variabel - variabel yang dianggap berpengaruh yang akan diproses sebaliknya untuk variabel - variabel yang dianggap tidak berpengaruh dibuang dari model. Proses akan dihentikan ketika semua variabel yang terpilih telah masuk[4].

\subsection{Particle Swarm Optimization (PSO)}

PSO merupakan model atau teknik optimasi berbasis populasi yang dikembangkan oleh Eberhart dan Kennedy tahun 1995, metode ini inspirasi dari perilaku sosial kawanan burung dan ikan [5]. Menurut Salappa, Doumpos, \& Zopounidis, PSO bisa diamsumsikan sebagai sekawanan burung mencari makanan disuatu daerah. Burung tersebut tidak mengetahui keberadaan makanan, tetapi mereka mengetahui jarak makanan ituberada, sehingga strategi yang paling baik untuk mendapatkan makanan tersebut yaitu mengikuti burung terdekat dari makanan tersebut[6]. 


\subsection{Root Mean Square Error (RMSE)}

Untuk melihat hasil prediksi dan mengetahui keakuratan hasil prediksi yang telah dilakukan terhadap data sebenarnya perlu dilakukan suatu evaluasi. Beberapa metode dapat digunakan untuk melakukan perhitungan kesalahan peramalan diantaranya adalah Root Mean Squared Error (RMSE). RMSE merupakan metode yang cukup sering digunakan dalam mengevaluasi kinerja prediksi. Dengan menggunakan RMSE, error yang ada menunjukkan seberapa besar perbedaan hasil estimasi dengan hasil yang akan diestimasi. Adanya keacakan pada data atau karena tidak mengandung estimasi yang lebih akurat adalah hal yang membuat perbedaan pada hasil. RMSE merupakan mengakarkan nilai dari MSE yang sudah dicari sebelumnya. RMSE digunakan untuk mencari nilai keakurasian hasil prediksi dengan data history dengan menggunakan rumus yang ditunjukkan dengan nilai kesalahan. Semakin kecil nilai yang dihasilkan semakin bagus pula hasil prediksi yang dilakukan. Rumus RMSE dipresentasikan pada persamaan[7].

\subsection{Data Time Series}

Data time series adalah nilai suatu variabel yang dikumpulkan atau dicatat berdasarkan urutan/deret waktu dalam bentuk satuan harian, mingguan, bulanan, atau tahunan dan di beberapa kasus terdapat jam tergantung keperluan terhadap perilaku data yang akan diobservasi. Data time series yang digunakan adalah data historis yang diukur berdasarkan suatu pengamatan tertentu. Karena data yang digunakan adalah data yang terukur, maka peramalan secara time series, termasuk ke dalam peramalan kuantitatif. Metode prediksi time series beranggapan bahwa data atau kejadian masa lalu akan cenderung berulang dimasa yang akan datang. Fokus prediksi secara time series adalah apa yang akan terjadi, bukan mengapa hal itu terjadi [8].

\section{Hasil dan Pembahasan}

Dalam melakukan eksperimen, peneliti melakukan beberapa tahap. Langkah awal pada suatu penelitian adalah pengumpulan data. Data yang digunakan pada penelitian ini adalah data set Sales Order Minyak Kelapa PT. Multi Nabati Sulawesi Unit Maleo. Data yang diperoleh berupa data jam time series univariat. Data tersebut berupa data jumlah penjualan minyak kelapa yaitu data set dari tahun 2012-2014. Data set tersebut untuk hari minggu tidak terjadi transaksi penjualan serta tanggal merah setiap tahunnya kosong dan terdiri dari variable Quantity dengan 635 record yang berasal dari PT. Multi Nabati Unit Maleo Gorontalo.

Data yang diperoleh berupa data univariat times series yang berupa numerik yaitu data jam, kemudian susunan data tersebut dirubah kedalam bentuk data harian sehingga diperoleh dataset sebanyak 635 record. Setelah mengubah data univariat time series yang berupa data jam ke data harian kemudian data diurutkan dari ascending menjadi descending. Selanjutnya data descending diolah dengan metode normalisasi.

Dataset yang telah dinormalisasi masih bersifat univariat diubah lagi menjadi data time series multivariat kemudian dijadikan dalam beberapa variabel independent, misalnya 1 periode sampai 10 periode dengan masing-masing 1 variabel dependent. Tahap selanjutnya menentuka parameter neural network dengan memasukkan nilai training cycle dengan range 100 sampai 1000. Nilai learning rate dengan range 0,1 sampai 0,9 . Nilai momentum dengan range 0,1 sampai 0,9 . Menentukan jumlah input layer untuk melakukan pengujian dengan memasukkan 1 sampai dengan 10 jumlah inputan. Penentuan jumlah hidden layer adalah 1 dan menentukan neuron size dengan melakukan pengujian dengan memasukkan nilai dengan range 1 sampai 10 serta nilai training cycle, learning rate dan momentum pada pengujian sebelumnya.

Selanjutnya melakukan pengujian neural network dengan menentukan parameter terbaik yaitu dengan menggunakan tools rapidminer. Hasil terbaik dari parameter neural network yaitu nilai training cycle 500 , nilai learning rate 0,3 , nilai momentum 0,2 , nilai neuron size 6 . Berikutnya tahap seleksi dengan menggunakan forward selection fungsinya untuk memilih variabel-variabel yang benar-benar terbaik atau variabel yang signifikan agar memberikan hasil yang terbaik. Kemudian melakukan pengujian dengan neural nertwork dan forward selection, neural network dan backward elimination, neural network dan particle swarm optomozation kemudian membandingkan model tersebut hasil terbaik berdasarkan RMSE terkecil yang akan dipilih.

Model yang dipilih berdasarkan nilai Root Mean Square Error (RMSE) terkecil yang diperoleh dari hasil pengujian. Model tersebut yang akan digunakan untuk melakukan prediksi jumlah produksi minyak kelapa. Model dengan tingkat error terkecil terdapat pada tabel dibawah ini: 
ILKOM Jurnal Ilmiah Volume 9 Nomor 3 Desember 2017

Tabel1. Perbandingan Model

\begin{tabular}{c|c|c|c|c|c|c}
\hline Model Terbaik & $\begin{array}{c}\text { Variabel } \\
\text { Periode }\end{array}$ & $\begin{array}{c}\text { Training } \\
\text { Cycle }\end{array}$ & $\begin{array}{c}\text { Learning } \\
\text { Size }\end{array}$ & Momentum & $\begin{array}{c}\text { Neuron } \\
\text { Size }\end{array}$ & RMSE \\
\hline $\begin{array}{c}\text { Neural Network } \\
\text { Neural Network }\end{array}$ & 8 & 500 & 0,3 & 0,2 & 6 & 0,141 \\
$\begin{array}{c}\text { Forward } \\
\text { Selection }\end{array}$ & 8 & 500 & 0,3 & 0,2 & 6 & 0,120 \\
$\begin{array}{c}\text { Neural Network } \\
\text { Backward } \\
\text { Elimination }\end{array}$ & 8 & 500 & 0,3 & 0,2 & 6 & 0,144 \\
$\begin{array}{c}\text { Neural Network } \\
\text { PSO }\end{array}$ & 8 & 500 & 0,3 & 0,2 & 6 & 0,143 \\
\hline
\end{tabular}

Tabel 1 merupakn hasil perbandingan dari pengujian metode neural network, neural network dan forward selection, neural network dan backwar elimination, neural network dan particle swarm optimization. Pengjian dilakukan dengan terlebih dahulu menentukan parameter neural network yang terbaik, kemudian dataset diujikan berdasarkan parameter terbaik dari hasil pengujian sebelumnya. Berdasarkan tabel diatas dapat dilihat model yang akan digunakan untuk melakukan prediksi jumlah produksi minyak kelapa, model yang yang paling baik berdasarkan tingkat error terkecil yaitu neural network forward selection.

Pada tahap selanjutnya yaitu mengaplikasikan model terbaik yang telah diperoleh dari hasil pengujian sebelumnya. Data set yang akan diimplementasikan sebanyak 6 record untuk prediksi jumlah produksi selama 6 hari kedepan kedepan. Pada tahap proses pengolahan data yang telah dilakukan sebelumnya adalah data univariat dinormalisasi kemudian di ubah ke bentuk data multivariat. Untuk mendapatkan hasil jumlah produksi minyak kelapa yang sesungguhnya data hasil prediksi harian akan dilakukan proses denormalisasi. Denormalisasi data set adalah mengembalikan ukuran data yang telah dinormalisasi sebelumnya untuk mendapatkan data asli. Denormalisasi diterapkan pada hasil eksperimen data testing yaitu prediksi jumlah produksi minyak kelapa. Hasil denormalisasi data dpat diperoleh dengan persamaan rumus:

$$
\begin{array}{ll} 
& \multicolumn{1}{c}{\text { Denormalisasi }=Y(\max -\min )+\min } \\
\mathrm{Y} & =\text { Hasil Keluaran dari Pelatihan } \\
\text { Min } & =\text { Data Minimum } \\
\operatorname{Max} & =\text { Data Maksimum }
\end{array}
$$

Tabel2. Perbandingan Persentase Januari

\begin{tabular}{c|c|c|c}
\hline Januari 2015 & Hasil Prediksi & $\begin{array}{c}\text { Jumlah } \\
\text { Produksi }\end{array}$ & Persentase \\
\hline Tanggal 2 & 1603 & 2002 & $80,07 \%$ \\
Tanggal 5 & 1616 & 1890 & $85,50 \%$ \\
Tanggal 6 & 1602 & 1699 & $94,29 \%$ \\
Tanggal 7 & 1611 & 2371 & $95,95 \%$ \\
Tanggal 8 & 1605 & 1679 & $95,59 \%$ \\
Tanggal 9 & 1609 & 1700 & $94,65 \%$ \\
\hline \multicolumn{2}{|c|}{ Rata - Rata Persentase } & $91,01 \%$ \\
\hline
\end{tabular}

Tabel 2 merupakan tabel perbandingan persentase Januari, yaitu hasil prediksi jumlah produksi minyak kelapa berdasarkan penelitian yang telah dilakukan sebelumnya dengan hasil nilai aktual 
jumlah produksi minyak kelapa januari 2015, nilai tersebut berdasarkan hasil produksi yang telah terjadi. Dengan rata - rata persentase yang diperoleh yaitu $91,01 \%$.

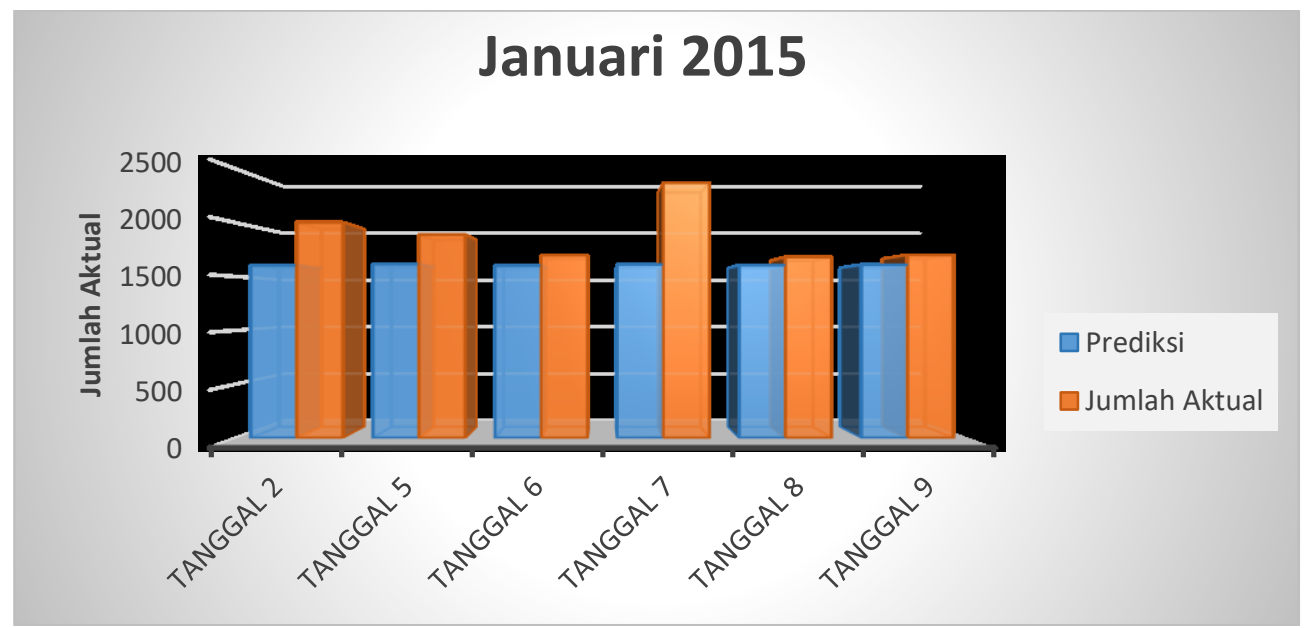

Gambar 2. Grafik Perbandingan Hasil Prediksi

\section{Kesimpulan dan Saran}

Berdasarkan pengujian yang telah dilakukan untuk prediksi jumlah produksi minyak kelapa, diperoleh parameter terbaik dari neural network dengan input layer 8, nilai training cycle 500, learning rate 0,3 , nilai momemtum 0,2 , serta nilai neuron size 6 . Hasil RMSE yang diperoleh neural network dan forward selection adalah 0,120. Dari hasil RMSE yang diperoleh menunjukkan bahwa pengujian menggunakan neural network dan forward selection lebih baik dibandingkan dengan pengujian yang hanya menggunakan neural network, neural network dan backward elimination, neural network dan particle swarm optimization. Dengan hasil tersebut dapat ditarik kesimpulan bahwa untuk prediksi jumlah produksi minyak kelapa menggunakan algoritma Neural Network (NN) dan forward selection sukses dilakukan. Dari persentase perbandingan hasil prediksi dan nilai aktual mencapai $91,01 \%$. Hasil dari penelitian ini dapat dijadikan sebagai bahan acuan bagi pihak perusahaan untuk pengambilan keputusan.

Saran untuk penelitian selanjutnya dapat menggunakan metode lainnya seperti, K-Nearest Neighbor, Support Vector Machine, dll, atau dengan menggunakan metode optimasi lainnya seperti Genetic Algoritm dll, serta melakukan pengujian dengan menggunakan data yang lebih banyak lagi agar hasil yang diperoleh lebih maksimal.

\section{Daftar Pustaka}

[1] Meida Arnela Effendi, Winarni, Woro Sumarni. 2012 "Optimalisasi Penggunaan Enzim Bromelin dari Sari Bonggol Nanas dalam Pembuatan Minyak Kelapa”, Universitas Negeri Semerang.

[2] Zunaidhi Rival, Wahyu S.J Saputra dan Ni Ketut Sari. 2012 "Aplikasi Peramalan Penjualan Menggunakan Metode Regresi Linear", UPN “Veteran” Jawa Timur

[3] Prasetya Eko. 2012, Data Mining - Konsep dan Aplikasi Menggunakan Matlab. Yogyakarta : Andi Yogyakarta, 72-73

[4] Intan Martina Md Ghani dan Sabri Ahmad. 2011 " Metode Perbandingan Regresi Linier Berganda Pada Pendaratan Ikan", Australia Jurnal IImu Dasar dan IImu Terapan, 5(1): 25-3

[5] T.-S. Park, J.-H. Lee, dan B. Choi. 2009 "Optimalisasi Jarinngan Syaraf Tiruan Dengan Daya Inertia Adaptif Particle Swam Optimization”, IEEE Konferensi Internasional Tentang Informatika Kognitif, pp. 481-485

[6] Mohammad,Badrul. 2013, "Prediksi Hasil Pemilu Legislatif DKI Jakarta dengan Metode Neural Network berbasis Particle Swarm Optimization", E-Journal Techno Nusa Mandiri Vol. IX, No 1, Maret 2013

[7] Rozzaqi Ade Ricky. 2015 "Naïve Bayes dan Filtering Feature Selection Information Gain untuk Prediksi Ketepatan Kelulusan Mahasiswa", Universitas PGRI semarang

[8] Purwanto, C. Eswaran dan R. Logeswara. 2011 "Sistem Inferensi Adaptif Neuro-Fuzzy yang Disempurnakan Untuk PrediksiTime SeriesHIV/AIDS, A. Abd Manaf dkk. (Eds.) : ICIES 2011, Part III, CCIS 253, PP. 1-13. 